\title{
NUEVAS Y VIEJAS REGULACIONES: UN ANÁLISIS DE LOS REGLAMENTOS DE CONVIVENCIA EN LA ESCUELA MEDIA
}

\author{
LUCÍA LITICHEVER (FLACSO) \\ LUCIANA MACHADO (UNCOMA) \\ PEDRO NÚNEZ (FLACSO) \\ SOLEDAD ROLDÁN (UNCOMA) \\ LEANDRO STAGNO (UNLP)
}

\begin{abstract}
RESUMEN
El presente trabajo se realiza en el marco de la investigación «Intersecciones entre desigualdad y educación media. Un análisis de las dinámicas de producción y reproducción de la desigualdad escolar y social en cuatro jurisdicciones». En este trabajo realizamos una comparación de los Reglamentos de Convivencia de las escuelas medias de las jurisdicciones de La Plata y Neuquén. A partir de la documentación recopilada y las entrevistas realizadas a los alumnos en torno a las normas escolares, nos interesa analizar de qué manera aquellas cuestiones que tradicionalmente reguló la escuela moderna, en especial la apariencia y la puntualidad perduran o son redefinidas en la actualidad. Asimismo, indagaremos en aquellas nuevas transgresiones previstas por la normativa. En conexión con las hipótesis del proyecto, sostendremos la presencia de formas de estructurar la convivencia en las escuelas, disímiles por jurisdicciones y sector social dando cuenta de la configuración y reconfiguración de la desigualdad.
\end{abstract}

Palabras ClaVe: TRANSGResiones, Escuela MEDia, JóVENES

* Los autores quisieran agradecer a Myriam Sothwell por la lectura realizada a una versión previa de este trabajo. E-Mail: educa@flacso.org.ar. 


\title{
RESUMO
}

O presente trabalho realiza-se no marco da pesquisa «Intersecções entre desigualdade e educação média. Uma análise das dinâmicas de produção e reprodução da desigualdade escolar e social em quatro jurisdições». Neste trabalho, realizamos uma comparação dos Regulamentos de Convivência das escolas médias das jurisdições da Plata e Neuquén. A partir da documentação e das entrevistas com os alunos sobre as normas escolares, interessa-nos analisar de que forma questões que tradicionalmente têm regulado a escola moderna, em especial a aparência e a pontualidade, perduram ou são redefinidas na atualidade. Do mesmo modo, averiguaremos as novas transgressões previstas pela norma. Em conexão com as hipóteses do projeto, sustentaremos a presença de formas de estruturar a convivência nas escolas, por jurisdições e setor social, dando conta da configuração e reconfiguração da desigualdade.

\section{PALAVRAS CHAVE: TRANSGRESSÕES, ESCOLA MÉDIA, JOVENS}

\begin{abstract}
This project is carried out within the framework for the investigation «Intersections between inequality and secondary education: an analysis of the dynamics of production and the reproduction of scholastic and social inequality in four jurisdictions». We carried out a comparison of the Regulations of Coexistence of the secondary schools of the jurisdictions of Plata and Neuquén. From the compiled documentation and the interviews carried out with the students regarding scholastic rules, it is of interest to us to analyze the ways which traditionally regulate the modern school, especially where appearance and punctuality persist or are redefined at present. At the same time, we will investigate new transgressions anticipated by the rules. In connection with the hypotheses of the project, we will maintain the presence of forms to structure the coexistence in the schools, dissimilar by jurisdictions and the social sectors taking into account the configuration and reconfiguration of inequality.
\end{abstract}

KEY WORDS: TRANSGRESSIONS, SECONDARY SCHOOL, YOUTH 


\section{INTRODUCCIÓN}

LOS REGÍMENES DISCIPLINARIOS DE la escuela media han comenzado a ser revisados en la mayoría de las jurisdicciones del país. En general, se trata de lograr una transición desde formas disciplinarias centradas en una autoridad burocrático-legal, ligadas al empleo de amonestaciones, suspensiones y firmas de actas, a otras formas reflexivas e individualizadas, fundadas en acuerdos, contratos o negociaciones establecidos entre los diferentes miembros de la comunidad educativa. Los reglamentos de convivencia se plantean como instrumentos que permiten mejorar la convivencia y generar mayores vínculos entre jóvenes y adultos, así como también trascender el carácter punitivo de la sanción prevista, a fin de lograr la reparación de la falta cometida frente a la transgresión de una norma.

Aunque con ciertas similitudes, estas modificaciones adquirieron particularidades distintivas en cada jurisdicción. A fin de proporcionar elementos que posibiliten posteriores estudios comparados, analizaremos el proceso llevado a cabo en Buenos Aires y en Neuquén. En términos educativos, ambas provincias han producido situaciones dispares luego de la sanción de la Ley Federal de Educación de 1993. Mientras que Neuquén no implementó las reformas previstas, la provincia de Buenos Aires fue una de las que más énfasis puso en las modificaciones en la gestión del sistema, los diseños curriculares y la organización pedagógica escolar previstas por la ley. De la misma forma, Buenos Aires sancionó recientemente una nueva Ley de Educación Provincial, enmarcada en la Ley Nacional de Educación aprobada este año.

En conexión con las hipótesis del proyecto de investigación donde se inscribe este trabajo, ${ }^{1}$ nos interesa analizar de qué manera las transgresiones que tradicionalmente reguló la escuela son reguladas en la actualidad, en especial, aquellas que hacen centro en la apariencia de los alumnos y el cumplimiento de los horarios escolares. Asimismo, consideraremos nuevas situaciones que se hacen presentes en el cotidiano escolar y que son objeto de regulación normativa. Hemos

1 «Intersecciones entre desigualdad y educación media. Un análisis de las dinámicas de producción y reproducción de la desigualdad escolar y social en cuatro jurisdicciones», Agencia Nacional de Promoción Científica y Tecnológica, Fondo para la Investigación Científica y Tecnológica, Programa Áreas de Vacancia, dirigido por Inés Dussel. 
constituido una muestra formada por doce escuelas, seis de Neuquén y seis de Buenos Aires, contemplando la presencia de instituciones privadas y públicas, de diferentes modalidades u orientaciones y cuyos alumnos provinieran de sectores sociales altos, medios y bajos. En este trabajo tomaremos en cuenta la normativa que regula la disciplina en cada escuela y las percepciones que los alumnos tienen de ella, recabadas mediante entrevistas.

\section{LA TRANSGRESIÓN DE LA NORMA EN LA ESCUELA. VIEJAS Y NUEVAS REGULACIONES}

En el marco de la constitución de los sistemas educativos nacionales, la escuela obligatoria se definió como un espacio civilizador que facilitó la regulación de conductas y hábitos de los escolares y, a partir de ellos, las del resto de la población (Varela; Álvarez Uría, 1991). El patrón civilizatorio sostenido codificó un conjunto de normas vinculadas a las prerrogativas de un orden social moderno, pensadas como universales y uniformes. La utilización del tiempo y la apariencia de los alumnos y los docentes fueron aspectos incluidos en esta estrategia regulatoria.

El control del tiempo y la consecuente sanción a la impuntualidad fueron emplazados como formas de homogeneizar las prácticas escolares, en momentos donde fue característica la asociación entre homogeneización, igualdad y democratización. La misma asociación explicó el uso de uniformes escolares desde las primeras décadas del siglo XX. Existía un consenso relativo a la regulación de los cuerpos en la escuela que señalaba la importancia de vestuarios y apariencias homogéneas como una forma de construir la nación, de consolidar un particular igualitarismo y de extender pautas de higiene. Al respecto, los guardapolvos o delantales blancos constituyeron un código dominante de vestimenta en las escuelas que intentó simbolizar la pureza y la igualdad y, asimismo, detectar fácilmente la trasgresión (Dussel, 2003).

La regulación de la conducta de los alumnos incluyó también las especificaciones relativas a la disciplina escolar. Diferentes intelectuales y expertos de la burocracia educativa manifestaron su oposición a las sanciones que involucraban castigos corporales. Aprobada la Ley 1420, el Consejo Nacional de Educación desarrolló diferentes medidas tendientes a sustituir los castigos directos sobre el cuerpo por otras formas disciplinarias que lograsen un equilibrio entre consenso y coerción. El Consejo exoneró de sus cargos a los maestros que apela- 
ron a estos castigos e instauró el ideal de un maestro como ejemplo de las conductas que debían caracterizar el orden escolar. El fin último de las nuevas formas sería la producción de jerarquías y diferencias entre alumnos y maestros (Puiggrós, 1990). Los reglamentos escolares redactados entre los últimos años del siglo XIX y los primeros del siguiente reflejaron estas nuevas propuestas. Un análisis comparado de las sanciones previstas demostró que la mayoría de ellos apeló a formas disciplinarias relacionadas con la separación de los alumnos de la escuela o el aula, su retención luego del horario de salida, la ampliación de tareas escolares, la privación del recreo o algún tipo de privilegio o recompensa, advertencias en privado o frente a los otros alumnos, aviso a las familias y la reorganización del espacio escolar. ${ }^{2}$

Las alternativas pedagógicas también formularon sus propuestas en torno a la disciplina escolar, tal fue el caso de la denominada Escuela Nueva. ${ }^{3}$ Más allá de las disidencias al interior del propio movimiento, los escolanovistas coincidían en la supresión de medidas disciplinarias tales como gritos, golpes de puntero o reprimendas en público y su reemplazo por prácticas relacionadas con un sentido de educación moral. Así, se apeló a reemplazar el control externo de los alumnos por la autorregulación de sus conductas, hecho que suponía una autoridad sustentada en las cualidades morales de los docentes. Aunque a través de la palabra y la imitación, la vigilancia continua no quedaba fuera de las estrategias previstas para conseguir el orden y formar sujetos reflexivos (Dussel; Stagno, 2004).

En la actualidad, las cuestiones vinculadas a las formas de construir un orden escolar y, específicamente, a la disciplina y la convivencia, han adquirido una especial importancia a nivel de la gestión del sistema educativo y de las prácticas cotidianas de las escuelas. El

2 Brener, Caruso y Mangone: «La disciplina escolar en los orígenes del sistema educativo argentino (1890-1916)». Informe de la cátedra Historia de la Educación Argentina y Latinoamericana, Universidad de Buenos Aires, mimeo, citado en Puiggrós, 1990.

3 La Escuela Nueva fue un movimiento de renovación pedagógica formado entre fines del siglo XIX y principios del XX que impugnó la acción impositiva y directivista de la pedagogía establecida. Sus integrantes sostenían la necesidad de centrarse en los intereses y etapas psicológicas del niño al momento de estructurar una propuesta curricular, en estrecha vinculación con las ideas de Rousseau. Asimismo, proclamaban a la espontaneidad y la libertad como principios de todo proceso de reforma educativa. 
tránsito por la escuela pone a los niños y jóvenes frente a situaciones de socialización que, tal como ocurre en otros ámbitos sociales, se caracterizan por el carácter ambivalente demarcado por la interrelación entre reciprocidad y hostilidad (Mouffe, 2007). Sin embargo, en los últimos años las imágenes de los medios de comunicación parecen destacar solamente este carácter hostil, mediante la difusión de situaciones protagonizadas por los jóvenes que expresan el melodrama de la inseguridad, la crisis permanente, la violencia entre pares, las muertes por gatillo fácil. Sin duda, estas imágenes condicionan las maneras de estructurar los vínculos al interior de las escuelas y de pensar la convivencia entre sus actores. Esto implicó, por parte de algunas instituciones, un esfuerzo por adecuar las normativas al nuevo escenario social.

Al respecto, podemos señalar la presencia de reglamentos de convivencia o de disciplina que suman nuevas normas a las pautas «tradicionales» de regulación, tendientes a «prevenir»y «castigar» conductas que se suponía no atravesaban la «aduana escolar» (Pineau, 2001). Los actores institucionales consignan en la letra de los reglamentos una serie de transgresiones factibles de ser cometidas por sus alumnos, en el cruce de múltiples representaciones acerca de los jóvenes que, como tales, difieren de acuerdo a las características locales de la escuela y la jurisdicción. En el marco de este trabajo, denominaremos «neotransgresiones» a las faltas relacionadas con la delincuencia, la drogadicción, la agresión física, la corrupción, la falsificación de la identidad, entre otras. Se trata de nuevas conductas que habitan (o se presupone que lo hacen) el actual escenario escolar que se traducen de manera diferente en cada una de las instituciones analizadas. La incorporación de nuevas normas da cuenta de una transformación al interior de la escuela media, particularmente, en relación con los cambios a nivel de las fronteras entre lo prohibido y lo permitido y de los parámetros aceptados por la imaginario social (Grimson, 2004).

\section{LOS REGLAMENTO DE CONVIVENCIA COMO ESCENARIO DE LA FORMACIÓN POLÍTICA}

En los reglamentos ${ }^{4}$ analizados podemos observar dos tendencias contrapuestas en lo que respecta a la regulación de las prácticas del día a día en los colegios, las normas establecidas y las transgresiones que

4 En el presente trabajo se utiliza en forma indistinta «reglamento»o «acuerdo» de convivencia. 
imaginan posibles de ser realizadas por los estudiantes. Por un lado, encontramos Reglamentos de Convivencia donde las normas propuestas se asemejan mucho a las que regulaba la escuela a principio de siglo. A estos reglamentos los llamaremos tradicionales. Por otro lado, hallamos algunos que incorporan nuevas cuestiones entre las pautas que regulan. A estos los denominaremos reglamentos en contexto. En los siguientes apartados presentaremos cada uno de ellos, indagando en el tipo de transgresiones que se estipulan.

\section{a) La persistencia de las normas tradicionales}

En el primer caso se trata de reglamentos que, si bien renovaron su estilo e incluyeron la estructura propuesta por el ente provincial para su redacción, regulan las mismas conductas que la escuela disciplinó desde su constitución. Cuando suponen conductas inapropiadas por parte de los estudiantes hacen referencia, básicamente, a la apariencia, la puntualidad y la higiene. Dos de los reglamentos de la muestra de Provincia de Buenos Aires y cuatro de la Provincia de Neuquén se incluyen dentro de esta categoría. Pese a las similitudes observadas, cabe destacar que existen diferencias entre ellos, tanto respecto a su vigencia como en su capacidad para delinear la convivencia en la escuela hoy.

Una de las escuelas donde las normas expresadas en el reglamento ponen énfasis en las normas tradicionales se encuentra ubicada en una localidad de la zona sur del Gran Buenos Aires, es de gestión pública de modalidad técnica y asisten a ella jóvenes de sectores populares. A partir de ahora la denominaremos V. El reglamento parece ser más el cumplimiento de un requerimiento formal ante la demanda del ministerio provincial de generar este tipo de documento que la respuesta a la necesidad de definir conjuntamente en la comunidad escolar las pautas compartidas de convivencia. En su fundamentación hace referencia al contexto histórico, social y económico actual y específico de la población que concurre a la escuela. Se señala que fue construido «teniendo en cuenta la historia de la escuela en esta zona del distrito». En forma consiguiente, se destaca que la creación de la escuela estuvo ligada al emplazamiento de una actividad industrial incipiente, interrumpida luego de las políticas económicas de la década de 1990. Desde estos cambios se explica la modificación observada en las características de la matrícula. Se realiza en la primera parte un diagnóstico de las transformaciones sociales y su impacto en la zona desta- 
cando que: «Las grandes transformaciones producidas en los últimos quince años condujeron a generar índices de desempleo sin precedentes en nuestro país, las migraciones internas que tornaron al distrito en receptor de los sectores excluidos de los principales centros urbanos determinaron la nueva conformación cualitativa de la zona, con predominancia de sectores ubicados bajo la línea de pobreza».

El Acuerdo de Convivencia caracteriza al contexto local como de violencia y de desocupación. Para prevenir ambas se promueve la integración y la inclusión social. A la vez, podría pensarse que la elaboración de dicho diagnóstico pareciera funcionar como explicación de las características de la población que asiste. Este análisis general, que permite situar a la escuela y a su población en un contexto específico, no parece relacionarse con la definición de las normas que se proponen en el acuerdo, al contrario, hallamos una falta de conexión entre lo que plantea y las situaciones que realmente afronta e intenta resolver la escuela diariamente.

El reglamento menciona de forma general, sin detallar, la necesidad de respetar aspectos relacionados con la «presentación personal». Este nivel de indeterminación no se condice con las frecuentes llamadas de atención de los preceptores, docentes y directivos a los alumnos respecto al uso de gorras y camisetas de fútbol, cuestiones muy exigidas y sancionadas pero no consignadas por escrito en el acuerdo.

Tal como lo señalamos, aunque el reglamento refiere que la violencia es una de las principales fuentes de conflicto tanto dentro como fuera de la institución, las normas no contemplan mecanismos que permitan abordar o resolver este tipo de situaciones. Afirma un alumno: «acá vienen de muchos barrios los pibes y se creen malos todos, no podés mirar a nadie porque ya... te vienen a apurar; y siempre se agarran los pibes, los pibitos más chicos de EGB, casi todos los días se agarraban». Los distintos entrevistados aluden a frecuentes peleas entre alumnos de distintas especialidades o años frente a las que, incluso, las autoridades han solicitado intervención policial. Tal es el caso de la oportunidad en la que dos grupos de alumnos se pelearon con cuchillos en la puerta de la escuela. Cuando preguntamos al preceptor por la transgresión cometida con mayor frecuencia por alumnos él respondió: «Es el tema de la violencia, de pelearse mucho, a veces por motivos insignificantes, de mirarse mal, haberse codeado en el pasillo, el tema de la violencia es muy grave, a veces traen también de afuera, los chicos van a bailar o algo afuera y ahí tiene un encontronazo y después se conocen que están acá, y transmiten eso mismo aquí 
adentro de la escuela». Es interesante indagar a qué mecanismos de resolución apelan y qué tienen a mano para hacerle frente a estas situaciones. Al respecto, un alumno alude a una pelea que se había iniciado fuera de la escuela entre dos compañeros, problema en el que uno de los profesores de taller intervino para resolverlo. Notamos de esta manera una descontextualización entre las normas estipuladas en el reglamento y la realidad que enfrentan, situación que obliga a los distintos actores a improvisar estrategias.

Otra de las escuelas de características similares respecto al tipo de normas previsto por el Acuerdo Institucional de Convivencia, es la que denominamos A. Es una escuela privada atípica, en tanto no se sostiene económicamente por la vía de una matrícula abonada por los alumnos, sino que depende del financiamiento provisto por la fábrica donde se ubica, en la cual los alumnos realizan las prácticas profesionales. La gran mayoría de los estudiantes tiene la posibilidad de insertarse laboralmente allí cuando concluyen sus estudios. Varios docentes son ex alumnos de la escuela y actuales empleados de la empresa.

El Acuerdo de Convivencia es presentado como «expresión de una fuerte vinculación de lo académico con lo laboral. La escuela es una sección más de la empresa, sin perder su identidad como institución educativa, brindando el ambiente y la contención necesaria que los alumnos requieren». Presenta a la disciplina como un hábito necesario para el trabajo y la define como una actitud de los alumnos de «aceptación de la institución educativa en todos sus aspectos, de las normas de convivencia que hacen posible la armonía necesaria con sus superiores, docentes, personal y compañeros, de las pautas culturales propias de la Nación, de integración y de respeto en cuanto a la idiosincrasia de cada una de las personas». En una parte del Acuerdo se especifica que «quien no tiene perspectivas de adquirir el hábito de un comportamiento adecuado a las exigencias laborales, tampoco podrá adquirir una formación y capacitación acordes con las necesidad de la Empresa en el área de recursos humanos». La letra del reglamento delimita así las condiciones exigidas para ser incluido en la comunidad construida.

Se trata de un reglamento que enfatiza la regulación de la apariencia y la puntualidad, donde la falta más grave parece ser «tirar tizas». Aunque estas características son similares a las definiciones del reglamento de la escuela $\mathrm{V}$, no se podría consignar una descontextualización de la normativa y su alejamiento de las situaciones cotidianas. Nos encontramos frente a una comunidad escolar endogámica y pe- 
queña y estricta en el cumplimiento de normas, características que nos llevan a pensar que se dejaría poco lugar a los «imprevistos» y posibles transgresiones de los estudiantes. En este ambiente de tanto control y de mirada atenta, las transgresiones parecen recortarse a un quantum específico. Los mismos estudiantes describen este microcosmos diferente «porque por ahí en otra escuela los pibes están fumando así... adentro del aula, están prendiendo fuego a las cosas... allá en [alude a una localidad vecina] dicen que prenden fuego a las cosas, a todo. Es cualquiera eso».

Las escuelas A y V se caracterizan por contar con reglamentos tradicionales pero presentan algunas diferencias. En el primer caso, se trata de una comunidad con rasgos endogámicos, con pocos alumnos y tradiciones sólidamente asentadas a lo largo del tiempo que redundan en la construcción de un espacio escolar fácilmente reconocible por los diferentes actores, donde no se conciben imprevistos. Si bien se parte de un diagnóstico de los cambios sociales ocurridos y su impacto en la zona, la escuela $\mathrm{V}$ mantiene un reglamento con pautas tradicionales que poco tienen para decir en relación a los hechos que diariamente necesitan resolverse. En este sentido, demuestra la poca adaptabilidad del formato escolar al nuevo contexto y deja lugar al desdibujamiento de la ley ante la necesidad de hacer frente a situaciones no contempladas, mediante la apelación a mecanismos y reglas informales.

En término de similitudes, en ambas escuelas se regulan y controlan más las actividades de taller que las desarrolladas en otros espacios. Existen normas específicas para este ámbito, en relación con la seguridad y el cuidado de los materiales, la vestimenta, la higiene, el recogimiento del cabello, entre otras, fundamentadas en el peligro del uso de las herramientas o maquinarias. En los talleres la tensión jerarquía-igualdad se juega en otros planos, por un lado se establecen relaciones de mayor horizontalidad entre alumnos y profesores, por otro hay poco cuestionamiento al saber transmitido.

En el caso de la muestra de escuelas de Neuquén, varias instituciones cuentan con reglamentos que regulan temáticas similares a las anteriores, aunque sus perfiles institucionales y las características de su población presentan grandes diferencias. La escuela $\mathrm{E}$ es de orientación técnica y está ubicada en el interior de la provincia. No tiene reglamento de convivencia ni documentos en donde consten las normas de la institución, sólo existe un Acta Compromiso que se entrega a los alumnos a principio de año y que debe ser firmado por ellos y por sus padres. El acta estipula las obligaciones de los alumnos, los 
padres y la escuela, sin especificar las que corresponden a los docentes. Si bien no hace referencia a la apariencia y la puntualidad, la escuela define una vestimenta obligatoria para los alumnos; los varones deben usar camisa, corbata y zapatos y las mujeres guardapolvo blanco. Las autoridades justifican la obligatoriedad de su uso como una forma de preparación para el ingreso al mundo del trabajo. Los alumnos entrevistados destacan que el uso del uniforme es el aspecto más exigido por la escuela, tornándose un terma controvertido que sigue generando debate al interior de la escuela. Otro estudiante señala a su vez la importancia de regular la puntualidad: «el día de mañana cuando estés trabajando no vas a llegar tarde porque es algo que aprendiste en la escuela secundaria ya que es algo que te lo exigían».

Podríamos pensar que la institución ha logrado generar un imaginario compartido en torno a lo que se considera una conducta «deseable», situación que se ve favorecida por el hecho de que muchos de sus docentes son ex alumnos de la escuela y, por lo tanto, habrían incorporado las normas escolares desde tiempo atrás. Así, podríamos sostener que la escuela promueve una socialización donde la discusión respecto a lo permitido y lo prohibido no aparece como una preocupación. Por otra parte, dentro de este imaginario compartido parece estar presente, como explicábamos más arriba, la idea de una preparación para el mundo del trabajo donde son exigidas y reforzadas las actitudes necesarias para desenvolverse en ese ámbito. Esto último no sólo es interesante por tratarse de una escuela técnica, sino porque parece estar marcada por las demandas de una intensa actividad económica petrolífera que ha identificado a la localidad. Esta marca identitaria de la comunidad se hace visible en la convivencia que plantea la escuela.

En relación a las sanciones, que tampoco se encuentran establecidas en el Acta Compromiso, un alumno comenta: «lo que hacen primero es un llamado de atención y después amonestaciones que es un tipo de puntaje maligno para el alumno porque al chico que se las ponen se queda tranquilo. Esas se van acumulando y cuando se juntan veinticinco lo expulsan». Cabe destacar que esta sanción se prevé para todas las trasgresiones en general, es decir, se piensa en una ley común que no permite la consideración de situaciones particulares.

Una institución que comparte algunos de estos rasgos es la escuela $\mathrm{S}$. Es la única escuela media de la comunidad, de gestión pública con Orientación Perito Mercantil y ubicada en una localidad del interior neuquino. Posee un documento denominado «Reglamento interno del establecimiento» en el que se regulan derechos de los alumnos, 
asistencia, deberes y obligaciones de los alumnos, faltas de conducta e higiene del establecimiento. Entre los entrevistados no hay un acuerdo respecto de la forma en que se elaboraron estas normas. ${ }^{5}$ De la misma forma, existe una idea vaga acerca de las conductas que las normas regulan y de las sanciones que se prevén.

En lo referente a la puntualidad, se concede una tolerancia de veinte minutos para los alumnos que, por razones de trabajo o distancia, no pudieran cumplir con el horario de ingreso. Una alumna entrevista expresa que la norma relacionada con la puntualidad es una de las más exigidas, ella se muestra conforme con esta exigencia argumentando que constituye un aprendizaje útil para la responsabilidad que implica la vida adulta. Por otro lado, la escuela fija la prohibición de llevar radios, equipos de música y celulares, salvo en casos de ser necesarios para una actividad escolar coordinada por los docentes. También se prohíben los juegos de mano y las «expresiones amorosas». Respecto de la vestimenta, se expresa que será «sobria y asea$d a »$, sugiriendo el uso de guardapolvos para las mujeres y el pelo recogido para varones y mujeres. Los alumnos no pueden asistir con musculosa, short o calzado «no adecuado», asimismo, el uso de gorros queda restringido al ámbito del patio. El reglamento considera como «faltas de conducta más frecuentes» el «desalineo personal en forma reiterada y no corregida; falta de aseo reiterada; uso de barba en varones y maquillaje en mujeres...».

Un alumno entrevistado, en concordancia con el lugar que ocupa este asunto en el reglamento, afirma que el aseo personal es el aspecto más exigido por la escuela y, particularmente, el uso del uniforme. Cabe destacar que sólo las mujeres están obligadas a llevar guardapolvo, aunque se prevé extender la obligatoriedad para todos los alumnos. En este sentido una alumna entrevistada afirma: «esto de usar uniforme está bueno, me gusta... porque de esa manera no habría problemas de que 'iuy!, viene la concheta, viene la pobre, viene la que tiene pla-

5 Uno de los alumnos entrevistados comenta que la elaboración del reglamento estuvo a cargo de la Dirección del establecimiento y expresa que le hubiera gustado participar en ese proceso. La alumna dice que el reglamento se «elaboró» y luego expresa que se estaría elaborando. Una de las docentes entrevistadas comenta que, al momento del trabajo de campo, la institución estaba reelaborando las normas escolares a partir del trabajo en grupos y poniendo a consideración de los docentes las decisiones a tomar. 
ta', entonces con el uniforme eso no se vería porque seríamos todos iguales». La importancia de la norma sobre el uniforme está fundamentada desde la posibilidad de resolución de un conflicto, como puede ser el de la discriminación, aunque dicha resolución parecería revestir un carácter casi instantáneo o lineal. En las afirmaciones de la alumna, es clara la asociación entre igualdad y homogeneidad, la misma que sustentó el uso obligatorio de guardapolvos en el marco de la constitución del sistema educativo (Dussel, 2003). Podríamos decir que no sólo es la percepción de la alumna, sino que la institución presenta al uniforme como una forma de evitar la discriminación.

En el documento no encontramos regulaciones sobre puntualidad y apariencia para los docentes y las autoridades. Las normas de los docentes se remiten a su Estatuto, las que estipula la institución se refieren únicamente al aspecto académico. Si bien se establece un tipo de sanciones que podrían caracterizarse como novedosas para el ámbito escolar, tales como la prohibición de realizar «juegos de manos», el uso del celular y equipos de música, no hay una pretensión de generar una nueva visión en torno a la convivencia escolar y la resolución de conflictos.

La tercera institución de la muestra neuquina que incluimos en el grupo de las que proponen reglamentos tradicionales es la escuela $\mathrm{C}$. Ubicada en un barrio de bajos recursos de la periferia de la ciudad de Neuquén, es de gestión pública y ofrece una orientación de Perito Mercantil. Durante el trabajo de campo no se obtuvo ningún documento en relación a normas de convivencia, asimismo, tanto los docentes como los alumnos entrevistados expresan no conocer normas escritas. Una docente entrevistada expresa «no sé si hay normas [...] en realidad todo está implícito [...] El tema de las llegadas tardes, el tema del respeto, la vestimenta (...) los chicos lo van cumpliendo porque se van acostumbrando [...]». Por su parte, la directora comenta que «había un reglamento hecho hace muchos años que nadie sentía como propio, entonces el año pasado se trabajaron tres o cuatro normas básicas». Entre las pautas trabajadas figuran el respeto, la escucha y las llegadas tarde.

Cuando se pregunta a los alumnos sobre la existencia de normas que no están escritas uno afirma: «la mayoría de las normas que se llevan adelante en los colegios ninguna está escrita, la única que debe estar escrita debe ser no romper el establecimiento porque del resto no hay nada $[\ldots]$ los profesores son los que te dicen respetar al compañero, todo ese tipo de cosas». En relación a esto, una alumna expresa «nosotros con cada profesor escribimos un par de pautas que nos parecen convenientes. Si se cumplen o no es otro tema, pero siempre las 
escribimos». Asimismo, comenta que no ha participado en la elaboración del reglamento ni conoce esta información.

Aunque no la define claramente, un alumno entrevistado parece asociar «conducta» con ciertas problemáticas propias del contexto de la escuela: «lo que se exige mucho es la conducta, hemos tenido varios problemas de conducta [...], un barrio marginal que la droga se ve mucho, el alcohol se ve mucho y hay muchos compañeros con muchos de esos problemas». Pese a que estas 'problemáticas' aparecen como fuertes preocupaciones en distintas entrevistas, la institución no prevé regulaciones en torno a las mismas. Si bien los sujetos dan cuenta del contexto conflictivo en el que la escuela se encuentra inmersa, parecen imaginar que esas problemáticas no van a atravesar la aduana escolar. Tanto las intervenciones de los alumnos como las de docentes y el director dan cuenta de una percepción sobre las normas que las reviste de un carácter natural y esencializado, en tanto construidas desde la fundación de la institución. No están escritas pero están desde siempre.

A diferencia de la escuela $\mathrm{S}$, la puntualidad está justificada por la formalidad de cumplir con la normativa provincial. La exigencia de puntualidad no está ligada a una intención disciplinaria de conductas de vida o preparación para el mundo del trabajo, sino a la responsabilidad de los docentes en relación a la permanencia del alumno en su hora de clase.

La última escuela que incluimos en este grupo es la escuela D. Se trata de una institución de gestión privada, religiosa, con cuatro modalidades de Bachiller. En su mayoría, los alumnos provienen de sectores medios y altos, de distintos barrios de la ciudad de Neuquén y de ciudades vecinas. No hay un reglamento de convivencia elaborado por escuela sino documentos que estipulan las normas previstas por la orden religiosa que la creó y que son comunes a todas las instituciones fundadas por ella. De esta forma, el proceso de elaboración no ha estado a cargo de la escuela y no hay en los entrevistados un conocimiento claro sobre las normas escritas vigentes.

El documento presenta afirmaciones de carácter abstracto y, si bien plantea que «su contenido está en un todo de acuerdo con la Ley Federal de Educación N ${ }^{\circ} 24195$ y las leyes provinciales», no da cuenta de los cambios en el contexto a lo largo del tiempo. Esto es coherente con la mirada religiosa en la que las normas poseen un carácter trascendental y por lo tanto se instituyen como dogmas, cuya discusión no aparece como una necesidad. En este sentido, frente a la pregunta por las normas que se suponen como más importantes, una alumna responde «esto que yo te decía de los valores, creo que respetar a los 
profesores». Por su parte, un alumno comenta no haber participado en la elaboración del reglamento ni conocer su existencia: «sé que a principio de año te dan uno que no sé si se llama de convivencia o normas no sé cuánto. Que es el que te dice que no podés salir tatatá, que no podes usar el celular, que tenés que venir con el uniforme, que tatatatatatá. Yo creo que son por ahí más normas generales, ahora de la convivencia viene más en si yo te falto el respeto, esas cosas, el trato, la verdad habría que averiguarlo. Y bueno, que si está o no está, no se hace conocer igual».

En el documento se alude al «cuidado en la presentación personal» pero no se explicita nada al respecto aunque en las prácticas los alumnos coinciden en señalar que el uso del uniforme es el aspecto más regulado por la escuela: «se puso más exigente últimamente con el tema del uniforme, que me parece que está bien». En cuanto a los docentes, se prescribe que deben caracterizarse por una «presentación digna».

La escuela se caracteriza por contar con muchos alumnos que son hijos de egresados y de actuales docentes, algo que permite generar un fuerte vínculo entre la escuela y las familias y una identidad institucional asentada en esta relación. Parecería haber una socialización endogámica en la que el contexto es percibido como lejano y diferenciado de este ámbito escolar. Esto se evidencia en el planteo de un alumno respecto a las diferencias que la escuela mantiene con otra de la zona: «tengo conocidos [haciendo referencia a chicos de otros colegios] que toman bebidas blancas en los recreos. En el pasillo, chicos que se empastillan, chicos que hacen el famoso... 'a tal hora salgo yo al baño, dejo el porro a la mitad, después viene la otra' [...] cosas que asustan y que son muy feas. Dentro de este colegio, por lo menos, [...] yo no te digo que no exista, porque la verdad que no sé. Sé que pasan otras cosas, la típica de chicos que fuman, el chico que llega un poco en pedo. Esas cosas pasan en todos los colegios. No deberían pasar, pero bueno, como que el colegio intenta todavía mantener un orden y un alumnado responsable».

\section{b) Reglamentos en contexto: neotransgresiones y nuevas preocupaciones}

En otras escuelas encontramos reglamentos de convivencia aggiornados a la época, a su contexto y a las características de sus alumnos. Algunos incluyen normas para nuevas posibles transgresiones, otros intentan generar maneras diferentes de abordar la convivencia que propicien la construcción de vínculos más cercanos dentro de las es- 
cuelas. La incorporación en la letra de un reglamento escolar de una serie de temáticas novedosas y, tiempo atrás inimaginables de ocurrir en la escuela, - drogas, portación de armas, bebidas alcohólicas, falsificaciones, robos, actos de corrupción, etc. - indica la presunción por parte de los actores institucionales de que, en un momento $u$ otro, ocurrirán. La percepción por parte de los docentes, preceptores y equipo directivo de que los alumnos pueden desplegar una serie de transgresiones novedosas, más allá de que realicen o no las mismas, lleva a plantear las interacciones de manera diferente. En algunos casos el temor determina relaciones con unos y no con otros alumnos, implica que alguien sea derivado al equipo de orientación para su seguimiento, a buscar pasarlo al nivel adultos o a separarlo de la institución. Incluso, en otros casos, incide en las calificaciones académicas y en la diferenciación con la que se aplican las sanciones.

Una de las escuelas que cuenta con reglamento con estas características, a la que llamaremos $\mathrm{M}$, se encuentra ubicada en la periferia de la ciudad de La Plata y recibe a jóvenes de sectores populares. La mayoría de los docentes y directivos consideran que la escuela se encuentra en una zona «de riesgo», imaginario que se traslada a los jóvenes. El cuaderno de comunicaciones de los estudiantes lleva pegado el reglamento de convivencia en sus primeras hojas. En este documento se hace referencia a las cuestiones tradicionalmente reguladas por la escuela: la vestimenta, la asistencia, la puntualidad, el cuidado de los materiales, el sistema de evaluación. Pero, a la vez, se especifican cuestiones vinculadas a los «miedos» de los docentes y autoridades de la institución en relación a la población a la que atienden. En este sentido, en la tipificación de las faltas «Muy graves» se describen una serie de cuestiones vinculadas a la violencia y la delincuencia: ${ }^{6}$ «ingresar con arma blanca o de fuego al establecimiento»; «ingresar con bebidas alcohólicas o sustancias alucinógenas»; «falsificación y/o destrucción de documentos (boletines, cuadernos de comunicaciones, libretas de calificaciones, etc.)»; «sustracción o robo de elementos de otros alumnos, del personal o de la escuela».

6 Cabe aquí destacar, tal como señala Gayol (2002), la necesidad de dar cuenta tanto de la pluralidad como de las diversas valoraciones de las violencias. En la actualidad, en la escuela media, aquello que tiende a ser considerado como violencia o delincuencia parecería obviar a los delitos financieros, muchas veces producidos por personas con alto nivel educativo. 
Entre las faltas que imaginan como posibles de ser cometidas por los alumnos se dejan traslucir no sólo los temores de los adultos, sino también una mirada específica sobre los jóvenes. En este sentido, resulta pertinente preguntarnos acerca de los miedos que circulan en las instituciones escolares. Ante el surgimiento en los últimos tiempos del miedo como problema social en sí mismo, Gabriel Kessler (2006) señala el lugar que cumple en la regulación de la vida local, ocupando el espacio que antes desempeñaba la organización fabril como principio regulador. Para el autor, el temor compartido regula horarios de entrada y salida del hogar, determina algunos caminos, lleva a evitar otros, genera límites infranqueables. ¿Qué ocurre con los temores circulantes en la escuela? ¿De qué manera condicionan los vínculos establecidos entre alumnos y docentes?

En la escuela M se percibe una tensión constante ante la posibilidad de que algo ocurra: una pelea entre alumnos, la agresión a un docente, algún hecho violento, por lo que se refuerza la mirada atenta y vigilante para prevenir la emergencia de estas situaciones. Para las faltas consideradas como «muy graves» las sanciones previstas son diez amonestaciones como mínimo, suspensión por 48 horas con trabajo de reflexión y, ante la reiteración de alguna de ellas, acta de compromiso y separación del establecimiento. Es claro que las problemáticas del contexto local aparecen en la escuela, aunque cabe preguntarse qué tipo de intervención representan las amonestaciones o suspensiones frente a situaciones como las descriptas y qué vínculos se pueden establecer cuando la mirada sobre los alumnos está centrada en los «peligros».

Con características diferentes, tanto en relación al sector social de proveniencia de sus alumnos como a la propuesta pedagógica que ofrece, podemos señalar que la escuela $\mathrm{N}$ también incluye neotransgresiones en su reglamento, aunque de otro tipo. Se trata de una institución pública, de gran prestigio en la ciudad de La Plata, a la que históricamente asistieron sectores medios provenientes de familias con un gran capital cultural. El reglamento de convivencia detalla las funciones de todos los actores institucionales, define claramente a los sujetos que regula, los requisitos que deben cumplimentar y sus obligaciones, tareas y responsabilidades. Es un estatuto amplio que organiza diversas cuestiones, tanto académicas como burocráticas, administrativas y de disciplina.

En el apartado sobre «Obligaciones y régimen disciplinario» se clasifican las faltas en leves, graves y gravísimas. Entre las primeras se incluyen las que caracterizamos como tradicionales: "Presentarse faltos de aseo y pulcritud en la indumentaria o con vestimenta inade- 
cuada»; «no observar modales adecuados»; «llegar tarde al aula luego del recreo». Cuando se especifican las faltas consideradas más graves se enumera una serie novedosa de transgresiones relacionadas con la mentira, la falsificación, la sustitución de alumnos, el robo y el ingreso al establecimiento de objetos que puedan causar algún daño. Estas nuevas reglas aparecen como espejo de situaciones que se dan en otros ámbitos sociales y políticos, nuevas normas que se vinculan estrechamente con el contexto. Sin embargo, los nuevos signos de época parecen traducirse de manera distinta en las escuelas M y N. Mientras en la primera el énfasis de las nuevas normas está puesto en la respuesta frente a la violencia y la delincuencia, en esta escuela el acento parece estar más en la autenticidad intelectual. No debe perderse de vista que esta escuela se ha dedicado históricamente a la formación de la elite intelectual de la ciudad, por lo cual el acento está puesto en la calificación, la persistencia de un sistema meritocrático y el acceso a los estudios superiores.

Incluimos también en este grupo a la escuela $\mathrm{L}$, institución privada a la que asisten jóvenes de clases medias y altas. En su reglamento parecieran combinarse las nuevas y viejas regulaciones. El documento define y ejemplifica cada uno de los conceptos que utiliza apelando a una yuxtaposición de discursos: los valores, la trascendencia, la formación, la responsabilidad. Define qué entiende por comunidad, convivencia, disciplina, indisciplina, sanciones. En cuanto a la disciplina, la concibe como «un requisito natural e indispensable para la existencia y desarrollo de una comunidad educativa. Es un hábito fundamental para fomentar la calidad de vida: significa establecer, compartir y respetar cierto orden, pautas y métodos para desempeñarse con miras a un fin común. Es, en definitiva EDUCACIÓN de nuestros impulsos menos racionales, de nuestra impaciencia, y de nuestras tendencias individualistas para subordinarlas a una meta que nos trasciende como meros individuos».

En referencia a la vestimenta, encontramos intentos de diferenciación entre quienes no asisten a esta institución y quienes sí lo hacen: «El uso de una misma indumentaria identifica a los integrantes de un grupo como tales, tanto entre sí como ante los demás [...]. Los alumnos del Colegio L se identifican por el uso de los colores blanco, azul oscuro, y rojo, y por un repertorio limitado de prendas cuyo diseño las hacen reconocibles como parte de su uniforme». En este sentido, la exigencia del uniforme implica, más que una búsqueda de homogeneidad del alumnado, el reforzamiento del carácter particular de la comunidad conformada, convirtiéndose en una marca de diferen- 
ciación respecto de otras instituciones y de otros jóvenes. Se constituye una comunidad distinta, especial, que busca preservar la formación educativa en un marco de socialización entre iguales. El reglamento interpela a los alumnos desde la pretensión de generar una identificación entre ellos y la institución apelando al uso de determinado color de ropa. En un contexto donde tienen lugar nuevos procesos de fragmentación social a partir de las tendencias de la clase media y media alta a generar espacios particulares (Svampa, 2005), el caso de la escuela L puede ser inscripto dentro de las estrategias educativas que se dieron estos sectores a la par de su ascenso y consolidación social (Del Cueto, 2004). Esta búsqueda, quizá no realizada por los jóvenes pero sí por sus familias, obliga a inscribir la estrategia de diferenciación en el marco de la fragmentación dentro de la clase media entre «ganadores» y "perdedores». Para continuar siendo parte de esa clase media, cercana al éxito, autónoma e independiente, es necesario acentuar la distinción respecto de otros, de allí la necesidad de subrayar el papel del uniforme.

En este colegio, la definición de nuevas normas que intenten regular las faltas que denominamos neotransgresiones parece originarse más por las situaciones concretas que ocurren en la escuela que por los miedos o imaginarios sobre sus estudiantes. El reglamento indica que son consideradas faltas «la tenencia de material pornográfico o de incitación a la violencia, la intolerancia y la discriminación de cualquier tipo y la apropiación de objetos ajenos», así como «el encubrimiento de la autoría de faltas graves de las que se tenga conocimiento fehaciente» y «la falsificación de firmas o anotaciones en documentos del Colegio», cuestiones estas últimas que hallamos también en la escuela N. A diferencia de las escuelas $\mathrm{M}$ y $\mathrm{N}$ mencionadas anteriormente, en este caso la incorporación de temas novedosos parece deberse a un seguimiento puntilloso de las acciones de los alumnos y a la pretensión de estipular toda clase de transgresiones posibles, más que al esfuerzo por contextualizar las faltas a la realidad de la institución. En este sentido, un alumno comentaba: «lo que pasa que también, nos ha pasado que hicimos algo nosotros y al año siguiente, a partir de lo que hicimos nosotros, yo y mi grupo de amigos, se inventa una regla más en el grupo de convivencia: no traer, no venir con... Entonces, hay muchas reglas»».

En definitiva, la escuela L parece combinar en su Reglamento una superposición de discursos tendientes a resaltar la distinción entre el marco de socialización propuesto y otras experiencias educativas. En este sentido, la formación pareciera orientada tanto a la internaliza- 
ción de la norma que el proceso de formación de un sujeto autónomo implica como a la construcción de una comunidad que refuerza su carácter distintivo frente a otras. Cuando son consultados acerca de las normas más exigidas, los alumnos dan cuenta de la construcción de un espacio escolar respetuoso entre alumnos y docentes en el cual los valores y el énfasis en el vínculo con el otro son parte esencial. Tal como señala un alumno, si bien «hay muchas reglas, la principal es la solidaridad, no faltar el respeto, ser buen compañero», ya que «una de las cosas principales es la solidaridad, lo que le prestan más atención. Después el respeto. Saber convivir, que no hay rollos».

Es importante resaltar que el alto nivel de regulación en la normativa no parece condecir con el clima más descontracturado del día a día escolar que se pudo percibir en el trabajo de campo. Las distintas situaciones fueron resueltas más a través del diálogo que remitiéndose al reglamento. Como relata un alumno ante alguna trasgresión «Te llevan a la preceptoría y te sientan, te dicen 'che, pará un toque, tomá la Coca, comete algo, tranquilizate porque siempre hacés lo mismo. Te tienen ahí... Pasa que te quieren como a un amigo'». Muestra de un modelo escolar que no sólo busca promover en los jóvenes que asisten al establecimiento el éxito y el valor de la competencia sino una mayor atención a lo afectivo (Del Cueto, 2004).

\section{c) La escuela como zona neutral}

En cada una de las jurisdicciones analizadas encontramos un tercer grupo de escuelas con rasgos distintivos en sus maneras de abordar la cuestión de la convivencia. Maneras que se reflejan en los modos de resolver los conflictos, las normas prescriptas en los reglamentos, su fundamentación y puesta en práctica de las mismas y las relaciones entre los actores.

En la Provincia de Neuquén una de las escuelas, es la que denominaremos $\mathrm{P}$, institución privada laica, formada hace catorce años por un grupo de padres y madres que buscaban una alternativa a las escuelas públicas del momento. En su mayoría, los alumnos provienen de sectores medios y medios altos y viven en diversos barrios de la ciudad de Neuquén y de ciudades vecinas. Al momento de realización del trabajo de campo, el Reglamento de Convivencia del colegio estaba siendo revisado, al igual que lo fue el Proyecto Curricular y las pautas de elección de abanderados. Al ingresar en primer año, el Colegio brinda a los alumnos un documento con las normas de convivencia que debe ser firmado tanto por ellos como por sus padres. 
No hay timbres que indiquen cambios de hora, recreos o finalización de jornada, por lo que en reiteradas oportunidades se manifiesta que alumnos y docentes deben 'aprender' a respetar los horarios. Al respecto, en el Reglamento se establece que «el alumno tiene la obligación de ser puntual en todas las actividades que se realicen en el colegio $[. .$.$] con respecto al horario de entrada, habrá una tolerancia de$ hasta diez minutos por un máximo de tres veces en el mes. Superado ese margen, la impuntualidad se computará como media falta». Cuando se le pregunta a una alumna entrevistada acerca de la norma más exigida en la escuela, ella menciona «no sé, cumplimiento horario (riéndose)», aunque aclara que mucho no se cumple esa exigencia. El profesor entrevistado sostiene: «como no hay timbre... entonces no hay nadie que me obliga, sé que tengo que estar. Que están obligados de todos modos a estar, pero es como un paso intermedio entre esta obligación sin la marca del timbre, sin la marca del parte, sin otras marcas, y la libertad de la universidad, donde si vas o no vas no le importa a nadie, el que se joroba sos vos, es un paso intermedio necesario»».

En relación a la apariencia, los docentes afirman: «a mí no me molesta ni que los chicos no tengan uniformes ni que no haya timbres, es decir, acá hay ciertas pautas que son diferente de otros colegios, aun colegios privados, particularmente con eso no tengo conflicto», «me parece bárbaro que los dejen ir vestidos como quieren, hay chicos que... qué sé yo... que tienen piercings, hay chicos que están tatuados, hay chicos que usan rasta... hay chicos que... eso en otro colegio es impensable».

Podríamos pensar que la falta de una normativa estricta y de sanciones minuciosas apela a una autorregulación de los alumnos que los hace responsables de sus acciones. Los entrevistados coinciden en señalar que la única sanción prevista es la suspensión temporal del establecimiento, en caso de una transgresión reiterada. El reglamento, en este sentido, estipula que «la sanción será proporcional a la falta cometida, pudiendo llegar a la expulsión ante falta gravísima o reiterada». En el mismo sentido expresa que «toda sanción debe tener un contenido pedagógico y, por lo tanto, debe dar origen a instancias de reflexión por parte del alumno», sin explicitar la sanción correspondiente a cada transgresión.

La falta de un detalle mayor acerca de las regulaciones estipuladas puede relacionarse con la identidad de la escuela fundada sobre la idea de un «ambiente familiar», construido sobre la base de un conocimiento mutuo de los distintos actores institucionales. En este sentido, la vicedirectora expresa: «no es una escuela que tenga mucha norma escrita, para nada, falta, falta letra pero porque en el fondo no 
hace falta; o sea, es una escuela que no tiene un reglamento [...], que más bien deja hacer, que más bien habla de todo lo que se puede hacer y que convoca mucho a la palabra y fortalece la palabra tanto con los chicos como con los adultos, los adultos tanto profesores como padres y así como última posibilidad deja la sanción en cuanto a suspensión [...] no hay un reglamento minucioso, hay normas que dicen en términos generales todo lo que no se puede hacer, pero todo eso que no se puede hacer está relacionado con valores que surgen de la escuela».

Un tema recurrente en las entrevistas es la 'pérdida de identidad' del colegio en relación al aumento de la matrícula y, por ello, el ingreso de nuevos docentes que no conocieron el proyecto del colegio desde sus inicios. Esto estaría generando una necesidad mayor de revisión del carácter general de las regulaciones y sanciones. En las normas de convivencia que se entregan al inicio del ciclo escolar se destaca el objetivo de favorecer la convivencia democrática, el rechazo a la discriminación, la defensa de los derechos y el cumplimiento de los deberes por parte de los estudiantes, el cuidado de la limpieza y del estado de las instalaciones, la promoción de una relación prolífica con el conocimiento y la libre expresión de los miembros de la comunidad.

En la Provincia de Buenos Aires, la escuela PL también formaría parte de este tercer grupo. Se trata de un bachiller de gestión pública al que asisten jóvenes de sectores populares. El reglamento tiene una organización y fundamentación bien claras y coherentes. El eje que lo recorre es el del respeto hacia el otro sin importar las jerarquías y la responsabilidad de cada cual. Desde allí se fundamentan las normas, tanto las tradicionales como las novedosas. A la vez, es claro como el aprendizaje es el orientador de estas pautas. Las mismas se prescriben con el fin de desarrollar valores en relación a la convivencia, a la conformación de una sociedad democrática, al respeto de las diferencias individuales y se propicia el aprendizaje en las maneras de vincularse con los otros. De esta manera, el contenido pedagógico no se desdibuja en la prescripción de normas. Otra cuestión interesante en este reglamento es cómo se concibe el conflicto, al que caracteriza como «algo inevitable y a la vez necesario». Reconocer el conflicto sin ocultarlo ni pretender evitarlo sino convivir con él e intentar resolverlo implica poder hacerse cargo de los problemas y afrontarlos. Esta es una pretensión diferente a la encontrábamos en otros. Este documento, por otra parte y a diferencia de otros, prescribe como sujetos de la norma a todos los actores institucionales delineando pautas de acción tanto para los alumnos como para sus familias, el personal directivo, docente y auxiliar. 
La puntualidad y el respeto de los horarios es una norma general solicitada para toda la comunidad educativa $\mathrm{y}$, al parecer, se inscribe más como una pauta que posibilite que el tiempo en la escuela sea efectivamente valioso más que como el aprendizaje de un hábito. A la vez, son contemplados los problemas con el escaso y defectuoso trasporte público de la zona por lo que no se les computa inasistencia a los estudiantes que llegan tarde por este tipo de dificultades. Los alumnos entrevistados destacan que respecto de la puntualidad «nunca hubo problemas», siendo las normas más exigidas, según una alumna entrevistada: «el respeto con los profesores, los compañeros... ya te digo, apuntan al tema de la convivencia». En este sentido, el reglamento explicita que: «procurar tener buen trato con todos implica evitar la descalificación, la burla y el trato despectivo hacia los demás». De esta manera, (y sumando para esta conjetura las observaciones realizadas en el trabajo de campo) reglamento y prácticas en el cotidiano escolar parecen ser coherentes buscando que para los alumnos el aprendizaje de la relación con los otros efectivamente sea central en su experiencia educativa, en la cual cobra importancia una matriz vincular donde el respeto es primordial como muestra de igualdad.

En cuanto a la apariencia el reglamento plantea: «procurar cuidar el aseo personal y adecuada presentación en el vestir constituye una muestra de respeto hacia el otro». A lo largo del trabajo de campo se ha podido observar que los alumnos cuentan con amplias libertades en lo que respecta a la vestimenta, constituyéndose en límite la falta de respeto hacia el otro que pareciera situarse en la cargada o la agresión por cuestiones vinculadas al fútbol. En este sentido, las autoridades son especialmente cuidadosas en evitar el uso de camisetas de fútbol de equipos rivales, tanto barriales como de las distintas divisionales del fútbol oficial a fin de evitar posibles enfrentamientos en base a la identificación futbolística?

Se desprende de las entrevistas con los alumnos que la escuela ha logrado reducir los niveles de violencia en una zona donde su uso se encuentra legitimado en las interacciones que ocurren en la cotidianeidad fuera de la institución escolar. Uno de los alumnos entrevistados nos cuenta que en la escuela «rara vez se pelean. Antes se peleaban mucho, pero ahora no», mientras que por su parte una alumna

7 Algunas investigaciones han señalado en el último tiempo como el fútbol se convierte en un lugar de identificación para los jóvenes y de escenificación de la violencia (Alabarces, 2000). 
señala que «no es mala esta escuela, no se llevan tan mal los chicos, en otras escuelas son más violentas». Estaríamos ante la construcción de un espacio escolar más seguro, confiable, que se diferencia de otras escuelas percibidas como violentas. La escuela, en un contexto aislado, plagado de múltiples violencias (tales como robos, peleas pero también la pobreza, la utilización política y el hambre) se convierten en «una zona neutral» en la cual los jóvenes, más allá del barrio o club deportivo de referencia, conviven sin mayores dificultades. Imagen de por sí interesante, ya que la convivencia en la escuela secundaria implica el desafío de tornar posible y grato ese «encuentro entre extraños» que la escolarización propone. De esta manera, la escuela parece reinstalar esa aduana escolar de la que hablábamos más arriba, pero adjudicándole otros sentidos: buscando que no sea sede del conflicto barrial pero tampoco pretendiendo evitarlo. El contexto penetra en la escuela pero lo que se intenta no es sancionarlo, sino trabajarlo para poder revertirlo.

En definitiva, pareciera primar una lógica cívica, que entiende a la educación como un derecho a garantizar. El espacio escolar, al poder ser apropiado genera un sentimiento de pertenencia de mayor intensidad en los alumnos y logra disminuir considerablemente los niveles de violencia.

También en la Provincia de Neuquén encontramos a la escuela J, que se distingue de otras por su intención de trabajar de manera diferente la cuestión de la convivencia. Se encuentra ubicada en un barrio de clase media-baja en una localidad del interior de la provincia y es de orientación técnica. El sistema disciplinario se encuentra establecido en un documento denominado «Normas de Convivencia. Los conflictos en el colegio. Tratamiento y prevención de los mismos». El proceso de elaboración fue coordinado por el equipo directivo. Se realizó un primer trabajo en el que cada curso debía hacer su propuesta en torno a las normas de convivencia y, a partir de ellas, la asesoría pedagógica redactó un documento que se puso a consideración de la comunidad educativa. Según uno de los alumnos, esta normativa «merece respeto»y, a diferencia de los alumnos de otras escuelas, demuestra un conocimiento total del proceso de elaboración de este proyecto.

Este documento no es definitivo, en tanto todos los años se pone a disposición de los padres para su revisión. El proyecto estipula lo que pueden y deben hacer alumnos y docentes y lo que no pueden y no deben hacer, los temas a acordar dentro del aula en el contrato pedagógico con cada profesor; las funciones de los cuerpos colegiados, ${ }^{8}$

8 Se trata del Consejo Consultivo y el Consejo de Curso. 
normativa y procedimientos acordados. En la fundamentación del proyecto se expresa que «Cada uno/a de los actores/actrices es responsable por las violaciones a las normas de convivencia. [...] Proponemos 'la negociación' como una actividad para resolver los problemas del colegio, donde se trata de superar los intereses opuestos mediante el compromiso mutuo, pactos y acuerdos. Los mismos deben quedar documentados».

Se hace una diferencia entre medidas disciplinarias 'convencionales' y 'no convencionales' vigentes. Las «Medidas disciplinarias 'convencionales'» son las dispuestas en el Reglamento General de Escuelas Técnicas: suspensión temporaria del establecimiento, amonestaciones, pérdida de la regularidad (libre por amonestaciones), expulsión del colegio o del sistema educativo. Las acciones que pueden ser sancionadas con suspensión temporaria del establecimiento son: "agresión física o moral contra las personas [...] sustracción reincidente de útiles, pertenencias o materiales ajenos [...] ingreso de bebidas alcohólicas en el colegio [...] ingreso y/o distribución y/o consumo de drogas en el establecimiento». Se exponen los propósitos de las medidas 'no convencionales', entre los que se destacan: «promover el reconocimiento de los conflictos como situaciones inherentes a la interacción de personas [...] promover el respeto hacia los principios consagrados en la Convención Internacional de los Derechos de los/as Niños/as y también hacia las Leyes Provinciales 2302 y 2212 [...] procurar que los procesos de construcción e internalización de las normas escolares se conviertan en instrumentos privilegiados para la reflexión sobre la ética de la responsabilidad ciudadana». De la misma forma, se exponen los criterios en relación con las sanciones: «privilegiar la implementación de estrategias de prevención [...] valorizar el contenido pedagógico y reparador de las sanciones que se adopten por transgredir las normas de convivencia [...] contextualizar las trasgresiones de acuerdo con el rol, las circunstancias, la historia institucional y personal y la edad de los/as alumnos/as [...] dar o permitir el derecho a la defensa $[. .$.$] promover la reparación del daño [...] valorizar el$ reconocimiento del error [...] privilegiar el diálogo como estrategia para la resolución de conflictos y corrección de conductas».

En relación a las transgresiones, un alumno entrevistado expresa que «la descarga de un matafuego es lo peor que podés hacer en esta escuela porque tenemos todo un plan de seguridad y hubo concretamente un caso de un pibe que, boludeando, descargó un matafuego y bueno, le pusieron amonestaciones y bueno, se rompe un vidrio o se escapa de la escuela o sale bueno, dentro de lo más estricto, después 
todo lo demás es prácticamente discutible». Aquí se puede observar la fundamentación de la transgresión en relación a la seguridad y a un proyecto colectivo del cual los estudiantes son parte. Una de las alumnas, si bien tiene una visión crítica acerca de las normas de la institución, «la falta de límites» señala que: «si una profesora te hace un acta y yo no estoy de acuerdo con lo que ella dice 'no, no te la firmo, y no te la firmo, firmala vos si querés. Yo no la voy a firmar y si la firmo yo te hago un acta a vos'». En relación a esto último, se puede observar la posibilidad de 'defensa' que tienen los estudiantes frente a la palabra de los docentes, por lo que no están obligados a firmar el acta de disciplina, siendo ésta una de las medidas previstas como apercibimiento escrito. El reclamo de esta alumna puede leerse como expresión de un contexto fuertemente cargado de sentidos ligados a dos instituciones centrales en la vida de esta localidad como son la iglesia y el ejército, lo cual hace que la escuela sea vista por la comunidad como una institución que transgrede 'lo esperado' desde estas concepciones.

En el proyecto de convivencia se estipulan los «Temas a acordar dentro del aula en el contrato pedagógico con cada profe»: usar gorra en el aula, tomar mate, elegir entre diferentes opciones de trabajo, escuchar música y comer, entre otras. En el reglamento de esta escuela, se explicita, en relación a la puntualidad, que los/as alumnos «deben llegar a horario» y que los/as docentes «no deben/no pueden llegar tarde» y se establecen las medidas disciplinarias en relación a las trasgresiones. Queda clara la forma en que el orden normativo ha comenzado a ser un campo de disputas, posibilitando acciones que antes eran impensables dentro del ámbito escolar o, al menos, permitiendo su discusión. En relación a esto, un alumno comenta «se suele plantear desde los estudiantes y los docentes, las dos partes y se reúne en el horario de clases, se juntan y se redacta y sino se llega a un acuerdo se pide la intervención de los directivos y se vuelve a discutir hasta llegar a un consenso. A partir de ahí se atiene cualquier conflicto al acuerdo pedagógico interno, y sino al escolar». Sin embargo, en la práctica algunos docentes se resisten a realizar estos acuerdos.

En relación a la vestimenta, se establece que «los alumnos pueden venir vestidos como quieran, que permita trabajar adecuadamente en clase (respetando las reglas específicas para taller y laboratorio)». Aparece aquí una especie de fundamentación respecto a cual es la vestimenta «adecuada» - carácter que puede no ser interpretado de igual forma por las distintas instituciones-, en tanto se mencionan las reglas del taller y laboratorio donde la vestimenta tiene que ver con las condicio- 
nes de seguridad en el trabajo de alumnos y alumnas. Si bien la adecuación de la vestimenta, según lo mencionan las normas, se funda sobre la posibilidad de «trabajar adecuadamente en clase», lo cual tendría su fundamentación en el caso del taller y el laboratorio, cabría preguntarse aquí a qué se refiere la norma cuando habla de «trabajar adecuadamente», en tanto incurre en una ambigüedad que podría dar lugar a diferentes interpretaciones por parte de alumnos/as y docentes.

\section{REFLEXIONES FINALES}

El análisis de los reglamentos y las interacciones cotidianas en las escuelas permite observar una disparidad de situaciones en cuanto a las normas que regulan la convivencia. En primer lugar, a diferencia de Neuquén, la Provincia de Buenos Aires cuenta con una normativa general que establece los pasos a seguir por las escuelas. Si bien la mayoría de las instituciones cuentan con Reglamentos de Convivencia, las nuevas prácticas no fueron internalizadas por toda la comunidad ni parece concebirse el reglamento como una manera pertinente para resolver las situaciones que enfrentan.

En algunos casos, los reglamentos que contienen pautas tradicionales están descontextualizados de la realidad que enfrenta la escuela, mientras que en otros la institución parece conservar una estructura para las cuales este tipo de reglamentos preserva su utilidad pero dificulta enfrentar otras realidades. Los reglamentos permiten analizar las representaciones vigentes acerca de los jóvenes que asisten a las escuelas. La lectura de los mismos permite afirmar que los órdenes normativos previstos instalan diversas desigualdades, en tanto un perfil de jóvenes aparece como peligrosos y posibles delincuentes — vinculando pobreza y violencia-, otros como ingenuos en sus transgresiones y algunos como falsificadores o corruptos, generalmente los que concurren a escuelas de sectores de clase media y media alta.

En el caso de la Provincia de Neuquén podría pensarse, a modo de hipótesis, que la falta de revisión de los marcos normativos estaría potenciando una convivencia basada en normas tácitas que apelan al sentido común que los sujetos (escolarizados) han construido acerca de lo correcto/incorrecto, permitido/prohibido y, en este sentido, a normas con un valor esencializado. Esta característica del sistema educativo provincial es un potencial factor de desigualdad, dado que, en tanto no existen marcos comunes elaborados y legitimados por la comunidad escolar, se amplía el margen de actuación institucional según criterios arbitrarios. 
Por último, los casos de las escuelas de $\mathrm{J}$ y $\mathrm{P}$ de la Provincia de Neuquén y PL de la Provincia de Buenos Aires muestran otras formas de estructurar la convivencia y de resolver los conflictos. Estas escuelas hacen referencia en sus reglamentos a los derechos de los alumnos, lo cual habla de una concepción diferente respecto de los sujetos que regula. Además, sus acuerdos son los únicos que involucran a los adultos de la escuela en la ley que rige las interacciones cotidianas. En los casos de las escuelas J y PL, a las que asisten jóvenes de sectores populares, existen posibilidades de cuestionar algunos aspectos de la dinámica escolar, así como relaciones más democráticas entre jóvenes y adultos. Aquí encontramos que si bien el contexto es de una alta desigualdad social, la escuela hace intentos por no producir ni reproducir nuevas desigualdades.

Es importante destacar que el modo de construcción de los reglamentos de convivencia en las escuelas dice mucho acerca de la formación política que las mismas pretenden. Los niveles de participación y los sujetos implicados en el proceso de elaboración de las normas institucionales dan cuenta de las voces habilitadas. De la misma forma, en la participación de distintos actores institucionales se trasluce la concepción de norma que la institución sostiene y el sentido que les da a las mismas. Además, lo que se visualiza como trasgresión guarda relación con los temas que la escuela instala como problemáticas, lo cual nos permite revisar de qué forma la institución desnaturaliza o no las conductas y las relaciones que se dan en la convivencia escolar. Aquello que se define como transgresión es producto de una construcción social, cambiante de acuerdo al contexto y a los tiempos históricos y, por lo tanto, en estrecha relación con una mirada específica sobre la juventud para la que imagina trayectorias desiguales de acuerdo a la representación construida.

BuENOS Aires (ARGENTINA), OCTUBRE 2007

RECIBIDO: DICIEMBRE 2007

ACEPTADO: MARZO 2008

\section{REFERENCIAS BIBLIOGRÁFICAS}

Alabarces, Pablo (2000): «Crónicas del aguante. Violencia, masculinidad y cultura de las clases populares en el fútbol argentino». Ponencia presentada en el «Encuentro Anual de Investigación». Universidad Nacional de General Sarmiento, Los Polvorines. 
COMPÈRE, MARIE-MADELeine (2000): «Historia del tiempo escolar en Europa». JUlio RUIZ BERRío (org.): La cultura escolar en Europa. Tendencias emergentes. Madrid: Biblioteca Nueva.

Del Cueto, Carla (2004): «Estrategias educativas de las nuevas clases medias en urbanizaciones cerradas del Gran Buenos Aires». Espiral. Estudios sobre Estado y Sociedad, Vol. XI, Nº 1 . Guadalajara.

DUSSEL, INÉS (2003): «La gramática escolar de la escuela argentina: un análisis desde la historia de los guardapolvos». Anuario de la Sociedad Argentina de Historia de la Educación $\mathrm{N}^{\circ} 4$. Buenos Aires.

— y LeandRo Stagno (2004): «'Ni cárcel ni cuartel'. Debates sobre disciplina y gobierno en el escolanovismo argentino a través de la revista La Obra (1920-1940)». «XIV Jornadas Argentinas de Historia de la Educación». Universidad de Buenos Aires, Facultad de Filosofía y Letras, Facultad de Ciencias Sociales y Universidad Nacional de Luján, Departamento de Educación.

GAYOL, SANDRA (2002): «Elogio, deslegitimación y estéticas de las violencias urbanas». SANDRA GAYOL y GABRIEL KESSLER (comp.): Violencias, delitos y justicias en la Argentina. Buenos Aires: Manantial y UNGS.

GRIMSON, ALEJANDRO (comp.) (2004): La cultura en las crisis latinoamericanas. Buenos Aires: CLACSO.

KESSLER, GABRIEL (2006): «Inseguridad subjetiva, sociedad y política: aportes para un debate latinoamericano». Javier Moro (editor): Juventudes, violencia y exclusión. Ciudad de Guatemala: Magna Terra Editores.

LiTICHEVER, LUCÍA; NúÑEZ, PEDRo (2005) «Acerca de lo justo, lo legal y lo legítimo. Cultura política en la escuela media». Última Década $\mathrm{N}^{\circ} 23$. Valparaíso: Ediciones CIDPA.

Mouffe, Chantal (2007): En torno a lo político. Buenos Aires: FCE.

Pineau, Pablo (2001): «¿Por qué triunfó la escuela?, o la modernidad dijo: 'esto es la educación', y la escuela respondió: 'yo me ocupo'». PABLO PINEAU, INÉs DUSSEL y MARCELO CARUSO: La escuela como máquina de educar. Tres ensayos sobre un proyecto de la modernidad. Buenos Aires: Paidós.

PUIGgRÓs, AdRIANA (1990): Sujetos, disciplina y currículum en los orígenes del sistema educativo argentino (1885-1916). Buenos Aires: Galerna.

SVAmPa, MARISTElla (2005): La sociedad excluyente. La Argentina bajo el signo del neoliberalismo. Buenos Aires: Taurus.

VARela, Julia y Fernando Álvarez (1991): Arqueología de la escuela. Madrid: La Piqueta. 